\title{
Lithium salts as leachable corrosion inhibitors and potential replacement for hexavalent chromium in organic coatings for the protection of aluminum alloys
}

\author{
P. Visser $\circledast^{1}$, Y. Liu, H. Terryn, J. M. C. Mol
}

(C) The Author(s) 2016. This article is published with open access at Springerlink.com

\begin{abstract}
Lithium salts are being investigated as leachable corrosion inhibitor and potential replacement for hexavalent chromium in organic coatings. Model coatings loaded with lithium carbonate or lithium oxalate demonstrated active corrosion inhibition and the formation of a protective layer in a damaged area during neutral salt spray exposure. The present paper provides an abridged overview of the initial studies into this novel inhibitor technology for the active corrosion protection of aluminum alloys. Coating defects were investigated by microscopic techniques before and after exposure to corrosive conditions. Scanning electron microscopy analysis of cross-sections of the coating defect area demonstrated that the protective layer comprises a typical threelayered structure, which included a dense layer near the alloy surface, a porous middle layer, and a flakeshaped out layer. Potentiodynamic polarization mea-
\end{abstract}

This paper was presented at the 11th Coatings Science International Conference (COSI) on June 22-26, 2015 in Noordwijk, the Netherlands.

P. Visser ( $₫)$, H. Terryn, J. M. C. Mol

Department of Materials Science and Engineering, Delft University of Technology, Mekelweg 2, 2628 CD Delft, The Netherlands

e-mail: p.visser-1@tudelft.nl

P. Visser

AkzoNobel, Performance Coatings, Rijksstraatweg 31, 2171 AJ Sassenheim, The Netherlands

Y. Liu

School of Materials, The University of Manchester, Manchester M13 9PL, UK

H. Terryn

Group of Electrochemistry and Surface Engineering

(SURF), Vrije Universiteit Brussel, Pleinlaan 2,

1050 Brussels, Belgium surements obtained with a microcapillary cell positioned in the coating defect area and electrochemical impedance spectroscopy confirmed the corrosion protective properties of these protective layers. The longterm corrosion inhibition of the lithium-based coating technology was tested in industrial coating systems.

Keywords Leaching, Corrosion inhibition, Aluminum, Coating, Lithium

\section{Introduction}

Aluminum alloys are used extensively in many industries and for many applications. Over the years, a wide range of aluminum alloys has been developed to address the performance requirements by the addition of alloying elements such as copper, magnesium, and/ or zinc. The favorable high strength to weight ratio makes alloyed aluminum specifically interesting for applications in the transportation industry.

The aircraft industry makes extensive use of highstrength aluminum-copper alloys (AA2XXX series) to optimize the aircraft design for fatigue properties, strength to weight ratio, and operational performance. ${ }^{1-4}$ The high copper content makes these alloys intrinsically more prone to corrosion compared to alloys without copper. ${ }^{5}$ Galvanic interactions of copper-rich intermetallic particles and the aluminum matrix make aluminum alloys, such as AA2024-T3 very susceptible to localized corrosion. ${ }^{6-11}$ Corrosion can occur in many forms on the aircraft structure (i.e., filiform, pitting, crevice, intergranular, galvanic, or stress corrosion), and although mechanistically different, these processes are similar in terms of their potential effects in reducing the structural integrity. ${ }^{2}$

The coating system is a key element when designing for corrosion control. ${ }^{12}$ The typical corrosion protective scheme for aluminum alloys in the aerospace industry 
comprises a chemical conversion coating or anodic film, covered by a primer with corrosion inhibiting properties and a topcoat. ${ }^{13,14}$ Such a scheme provides passive (barrier) and active (leaching and inhibition) corrosion protection. ${ }^{15}$ For decades, hexavalent chromium $(\mathrm{Cr}(\mathrm{VI}))$-based pigments and conversion coatings have been used to protect the high-strength aluminum alloys. ${ }^{16,17}$ Chromates are well-known for their corrosion inhibiting efficiency over a wide $\mathrm{pH}$ range and their ability to reduce the oxygen reduction reaction. ${ }^{18,19}$ Unfortunately, $\mathrm{Cr}(\mathrm{VI})$-based compounds are toxic and known carcinogens, and new regulations and legislations are restricting their current and future use. ${ }^{20-22}$ Over the years, extensive research has been conducted to find environmentally friendly alternative inhibitors that perform equal or better compared to $\mathrm{Cr}(\mathrm{VI})$-containing inhibitors. ${ }^{17,23-25}$ Among them, inorganic inhibitors such as molybdates, ${ }^{26}$ vanadates, ${ }^{27,28}$ permanganates, ${ }^{29}$ and rare-earth cations (such as cerium ${ }^{30,31}$ and praseodymium ${ }^{32}$ ) were investigated. Furthermore, several organic compounds, including benzotriazole, dibutylphosphate, and 2-mercaptobenzothiazole, and combinations with the inorganic inhibitors demonstrated corrosion inhibition on AA2024-T3. ${ }^{33-37}$ A new paradigm of chromate-free corrosion protection was the introduction of magnesium metal as sacrificial anode in a coating. ${ }^{38,39}$ Magnesium-rich primer (MgRP) technology provides cathodic protection to the aluminum alloy by galvanic coupling of the metallic magnesium pigment and the aluminum alloy. ${ }^{40,41}$ While the MgRP technology shows very promising performance, the industry still needs an alternative for chromate using the traditional leaching mechanism. Hence, the search for chromate-free inhibitor technology is continuing.

In the 1990s, lithium became of interest as a potential corrosion inhibitor after reports of passivity of aluminum when exposed to alkaline lithium salt solutions. ${ }^{42}$ This passivity is attributed to the formation of a continuous polycrystalline lithium-aluminum-hydroxide-carbonate-hydrate $\left(\mathrm{Li}_{2}\left[\mathrm{Al}_{2}(\mathrm{OH})_{6}\right]_{2} \cdot \mathrm{CO}_{3} \cdot n \mathrm{H}_{2} \mathrm{O}\right)$ film on aluminum exposed to such alkaline lithium solutions. ${ }^{43,44}$ Based on this phenomenon, Buchheit et al. ${ }^{45}$ developed a lithium-based chemical conversion coating process which increased the corrosion resistance of AA1100, AA6061T6, AA2024-T3, and AA7075-T6.

Visser and Hayes found that lithium salts could be used as leaching corrosion inhibitor in organic coatings. ${ }^{46} \mathrm{In}$ recent work, organic coatings loaded with lithium salts provided fast and effective corrosion protection in an artificial damage when exposed to neutral salt spray (NSS) conditions (ASTM B-117). ${ }^{47}$ It was found that lithium-ions were able to leach from the organic coating and generate a layer in the damaged area. ${ }^{47}$

This paper presents an abridged overview of the recent investigations into the application of lithium salts as leaching corrosion inhibitor in organic coatings for the protection of AA2024-T3, as presented at the Cosi Conference 22-26 June 2015, Noordwijk, The Netherlands. The overview provides insight into the lithium-based coating technology based on results generated from model coatings, describing the lithium effect and the characterization of the protective layer with microscopic techniques as published by Visser et al. ${ }^{47}$ Furthermore, the mechanistic aspects of the lithium technology such as lithium leaching, electrolyte conditions in the damaged area and formation of the layer will be discussed. The corrosion inhibiting properties were investigated with electrochemical impedance spectroscopy and the microcapillary cell. This work is complemented with examples of long-term NSS exposure results of industrial coating concepts.

\section{Experimental}

\section{Commercial materials}

Polyurethane model coatings were formulated from commercial raw materials and analytic grade materials:

- Desmophen 650 MPA. Branched, hydroxyl-bearing polyester, $65 \%$ in 1-methoxypropylacetate-2 (MPA), viscosity ca. $20.000 \mathrm{mPa} \cdot \mathrm{s}$ at $23^{\circ} \mathrm{C}$, hydroxyl content $5.3 \%$ equivalent weight $320 \mathrm{~g}$ (Covestro).

- Tolonate HDB 75 MX, Aliphatic polyisocyanate biuret (HDI homopolymer, $75 \%$ solids), viscosity ca. $250 \mathrm{mPa} \cdot \mathrm{s}$ at $25^{\circ} \mathrm{C}, \mathrm{NCO}$ content $16.5 \%$, equivalent weight $255 \mathrm{~g}$ (Vencorex).

- Tioxide TR92 $\left(\mathrm{TiO}_{2}\right)$, rutile, density $4.1 \mathrm{~g} . \mathrm{cm}^{3}$, oil absorption $18 \mathrm{~cm}^{3} / 100 \mathrm{~g}$ (Huntsman).

- Blanc Fixe N, Synthetic barium sulfate, density $4.5 \mathrm{~g} /$ $\mathrm{cm}^{3}$, oil absorption $13 \mathrm{~cm}^{3} / 100 \mathrm{~g}$ (Sachtleben).

- Lithium Carbonate, density $2.11 \mathrm{~g} / \mathrm{cm}^{3}$ (Sigma Aldrich).

- Lithium oxalate, density $2.12 \mathrm{~g} / \mathrm{cm}^{3}$ (Sigma Aldrich).

- Magnesium oxide, density $3.58 \mathrm{~g} / \mathrm{cm}^{3}$ (Sigma Aldrich).

- Dynasylan GLYMO, bifunctional organosilane (Evonik Industries).

The compositions of the industrial formulations are based on polyurethane and epoxy concepts utilizing the lithium coating technology. ${ }^{46}$ These concepts were exposed to $3000 \mathrm{~h}$ NSS exposure and compared against a chromated coating and a noninhibiting concept.

Tartaric-sulphuric acid (TSA) anodized AA2024-T3 unclad sheet material (0.8 mm 2024-T3 QQ-A250/5) from Alcoa was used for the experimental work. The TSA anodizing was performed according to aerospace requirements (AIPI 02-01-003) at Premium AEROTEC, Bremen Germany.

\section{Paint and sample preparation}

The pigmented model coatings, as described in Table 1, were prepared according to the following procedure: 
Table 1: Composition of reference and lithium salt-loaded model coatings

$\begin{array}{ccc}\begin{array}{c}\text { Noninhibiting } \\ \text { reference }\end{array} & \begin{array}{c}\text { Lithium } \\ \text { carbonate }\end{array} & \text { Lithium } \\ \text { (g) } & \text { oxalate }\end{array}$

\begin{tabular}{lrrr}
\hline Component A & & & \\
$\quad$ N-Butylacetate & 75.0 & 75.0 & 75.0 \\
Desmophen 650MPA & 47.7 & 47.7 & 47.7 \\
Lithium carbonate & & 23.6 & \\
Lithium oxalate & & & 32.0 \\
Magnesium oxide & & 16.4 & 16.4 \\
$\quad$ Tioxide TR 92 & & 5.9 & 5.9 \\
$\quad$ Blanc Fixe N(Ba( $\left.\left(\mathrm{SO}_{4}\right)\right)$ & & 15.4 & 15.4 \\
Component B & & & \\
$\quad$ Tolonate HDB 75 MX & 28.5 & 28.5 & 28.5 \\
Dynasilan Glymo & 5.2 & 5.2 & 5.2 \\
\hline
\end{tabular}

Component A was prepared by adding the individual raw materials under stirring in a $370 \mathrm{~mL}$ glass jar. After the addition of $400 \mathrm{~g}$ Zirconox ${ }^{\circledR}$ pearls (1.7$2.4 \mathrm{~mm}$ ), the pigments were dispersed to a particle size smaller than $25 \mu \mathrm{m}$ by 20 min shaking on a Skandex ${ }^{\circledR}$ paint shaker. After this procedure, the mixtures were filtered to remove the pearls.

Component B was mixed separately and added to Component A. The mixture was stirred to a homogeneous mixture. The coatings were applied using an HVLP (High Volume Low Pressure) spray gun on the AA2024-T3 unclad TSA panels, $30 \mathrm{~min}$ after mixing. After the application, the coatings were cured at $80^{\circ} \mathrm{C}$ for $16 \mathrm{~h}$, and the dry film thickness of the coatings was 20-25 $\mu \mathrm{m}$.

An artificial damage was made in the coating with a mechanical milling device from corner to corner. The U-shaped scribe was $1 \mathrm{~mm}$ wide and 100-150 $\mu \mathrm{m}$ deep into the metal.

\section{Experimental techniques}

\section{Neutral salt spray (ASTM B-17)}

After the scribing procedure, the samples were taped on the backside and exposed to the NSS conditions (ASTM-B117) for varying periods of time up to $168 \mathrm{~h}$ for the model systems and $3000 \mathrm{~h}$ for the industrial systems. After exposure, the samples were rinsed for 2 min with flowing deionized water to remove any residual chlorides and subsequently air-dried.

\section{Scanning electron microscopy (SEM)}

Cross-sectional observations of the scribed area was carried out by scanning electron microscopy (SEM) using a ZEISS Ultra 55 instrument with an acceleration voltage of $0.5 \mathrm{kV}$.
Electrochemical impedance spectroscopy (EIS)

The protective behavior of the lithium-based organic coatings was evaluated with EIS, using a threeelectrode set-up in a Faraday cage, equipped with a saturated calomel electrode as the reference electrode, platinum gauze as the counter electrode, and a scribed panel as the working electrode. A cylindrical tube with a $4 \mathrm{~cm}$ diameter was clamped to the scribed AA2024T3-coated substrates. The area exposed to the electrolytes was $12.5 \mathrm{~cm}^{2}$, the effective electrode or scribed area was $0.48 \mathrm{~cm}^{2}$, and the volume of electrolyte was $60 \mathrm{~cm}^{3}$. Coated alloy samples with a scribe before and after $168 \mathrm{~h}$ NSS exposure were immersed in $0.05 \mathrm{M}$ $\mathrm{NaCl}$ solution for $2 \mathrm{~h}$. Impedance measurements were taken at the free corrosion potential using an Autolab PGSTAT30 computer-controlled potentiostat, with $10 \mathrm{mV}$ sine amplitude and a frequency range from 0.01 to $3 \times 10^{4} \mathrm{~Hz}$.

\section{Electrochemical microcapillary cell technique}

Localized potentiodynamic polarization measurements were performed with the microcapillary cell technique using the equipment set-up as developed by Suter and Böhni. ${ }^{48}$ The glass microcapillary was pulled with a micropipette puller (Sutter Instruments Company) followed by grinding and polishing it to the required size. Subsequently, a deformable hydrophobic silicone gasket was prepared at the end of the microcapillary tip.

For this work, a capillary with an internal diameter of $100 \mu \mathrm{m}$ (exposed sample area of $7.85 \times 10^{-5} \mathrm{~cm}^{2}$ ) was selected to perform the measurements in the scribed area. The measurements were controlled by a high-resolution Jaissle IMP83 PCT-BC potentiostat. The set-up of the cell comprised a three-electrode configuration: the sample area as working electrode $\left(0.48 \mathrm{~cm}^{2}\right)$; a Pt counter electrode and an $\mathrm{Ag} / \mathrm{AgCl} 3 \mathrm{M}$ $\mathrm{KCl}$ as reference electrode. The anodic potentiodynamic scans were performed at a scan rate of $1 \mathrm{mVs}^{-1}$, starting $-50 \mathrm{mV}$ from the open circuit potential (OCP) and $5-10 \mathrm{~min}$ after the microcapillary was positioned. All experiments were performed in $0.05 \mathrm{M} \mathrm{NaCl}$ solution.

\section{Results and discussion}

\section{The corrosion inhibiting effect of lithium salts}

In 2015, the first observations of the use of lithium-based coating technology were published presenting the analysis of the corrosion protective layers, generated from lithium salt-loaded organic coatings. ${ }^{47}$ Figure 1 shows optical images of coated and scribed AA2024-T3 panels unexposed and after $168 \mathrm{~h}$ NSS exposure (ASTM B117). Figure 1a shows the pristine scribe prior to 

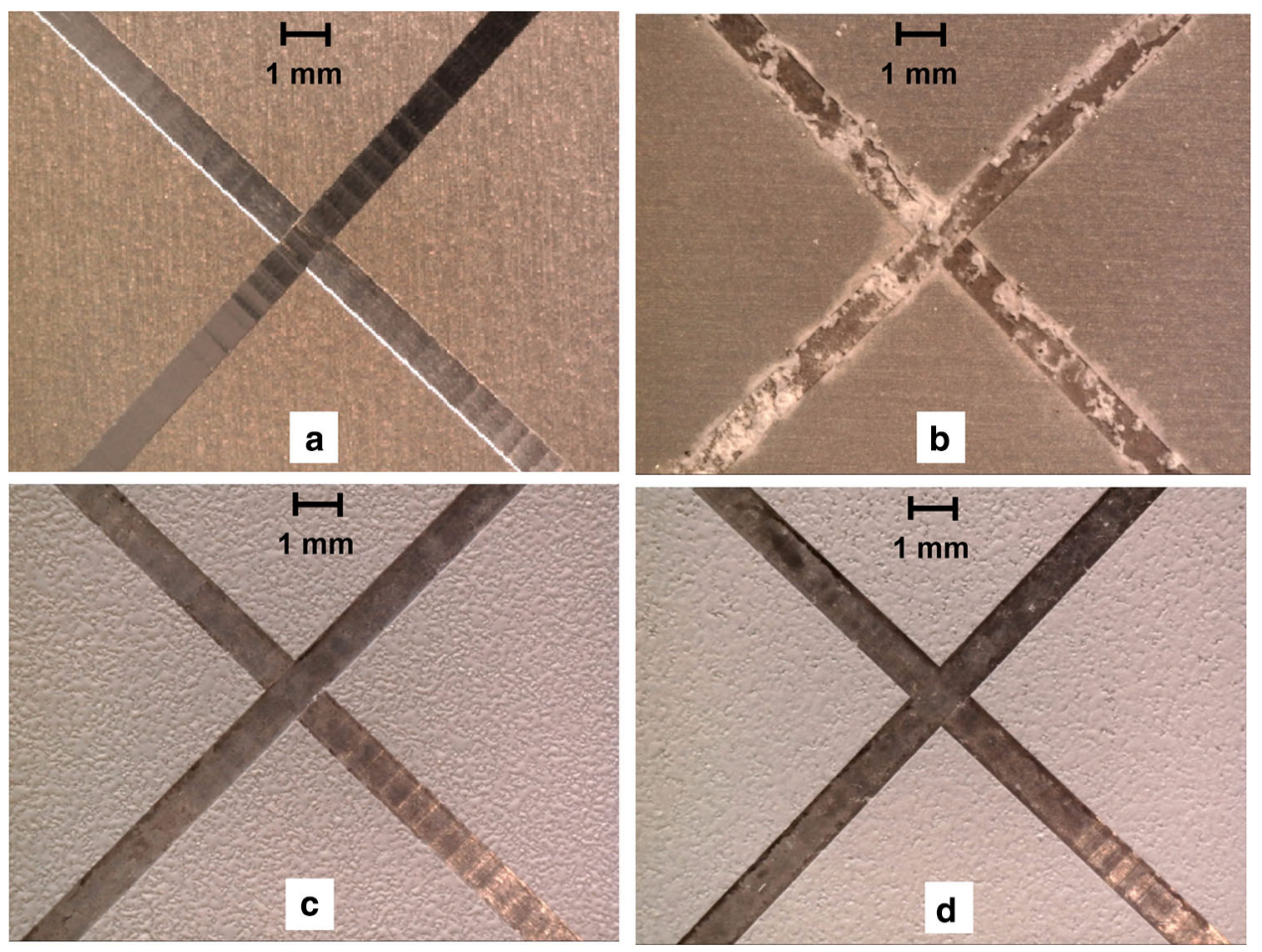

Fig. 1: Optical images of coated and scribed AA2024-T3 panels (a) unexposed; after $168 \mathrm{~h}$ neutral salt spray exposure (ASTM B-117) for the (b) noninhibiting reference, (c) lithium carbonate, and (d) lithium oxalate-loaded coatings ${ }^{47}$

exposure. The coating without lithium salts (Fig. 1b) shows an excessive amount of corrosion products in the scribed area after exposure. This is in contrast to the clean and shiny scribes of the samples with coatings loaded with a lithium salt (Figs. 1c and 1d). This observation and the visual comparison of the scribed areas demonstrate the corrosion inhibiting effect of coatings loaded with lithium salts upon coating damage.

Cross-sections were prepared to study the scribed regions of these samples in more detail with SEM. Figure 2a shows a cross-section of a sample with a Ushape scribed area and the organic coating with a typical thickness of $25 \mu \mathrm{m}$ evident on both sides on top of the aluminum. Figure $2 b$ displays the detrimental effect of exposure to corrosive conditions when a coating has insufficient corrosion protection. The scribe of the noninhibited sample shows large amounts of voluminous corrosion products distributed relatively homogeneously in the scribe. At higher magnification, the cross-sections show the porous corrosion products (Fig. 2c), which were identified with EDX as hydrated aluminum oxides and hydroxides. In addition, evidence of localized corrosion (Fig. 2d), such as pitting and intergranular corrosion, was observed. ${ }^{47}$

In contrast to the samples with a noninhibited coating, the scribes of the organic coatings containing lithium salts showed no significant amounts of corrosion products. Figure 3 a shows the image of a crosssection of the clean scribe of a sample with a lithium carbonate-loaded coating after 168 h NSS. Further- more, SEM investigations at increased magnifications revealed that the scribe was covered with a thin layer. Figures $3 b$ and $3 c$ show such a layer formed from a lithium carbonate-loaded coating, and no signs of pitting or intergranular corrosion were observed. Both the lithium carbonate and lithium oxalate sample show this deposition behavior. Higher magnification images of these protective layers demonstrate that these layers generated from lithium salt-loaded coatings have a thickness of 0.5 to $1.5 \mu \mathrm{m}$. The layers indicate a typical morphology. Top-view SEM micrographs reveal the porous columnar/petal-shaped surface of the layers (Figs. 4a and 4b). Cross-sectional analysis with SEM at higher magnifications point out that the layer comprises three distinct regions: a dense barrier region at the metal/deposited layer interface, a porous region in the middle, and a columnar outer region. ${ }^{47}$

Further analysis of the composition with transmission electron microscopy and electron energy loss spectroscopy revealed that these protective layers not only contain aluminum and oxygen, but also lithium was distributed relatively uniformly in the layer as well. ${ }^{47,49}$ These observations imply that the corrosion protection or inhibition of the scribed area may be attributed to this deposited layer that developed in situ throughout the scribed surface area. The presence of lithium in the protective layer suggests that lithium has been released from the coating matrix and has an active role in the formation of the protective layer in the scribed area. 

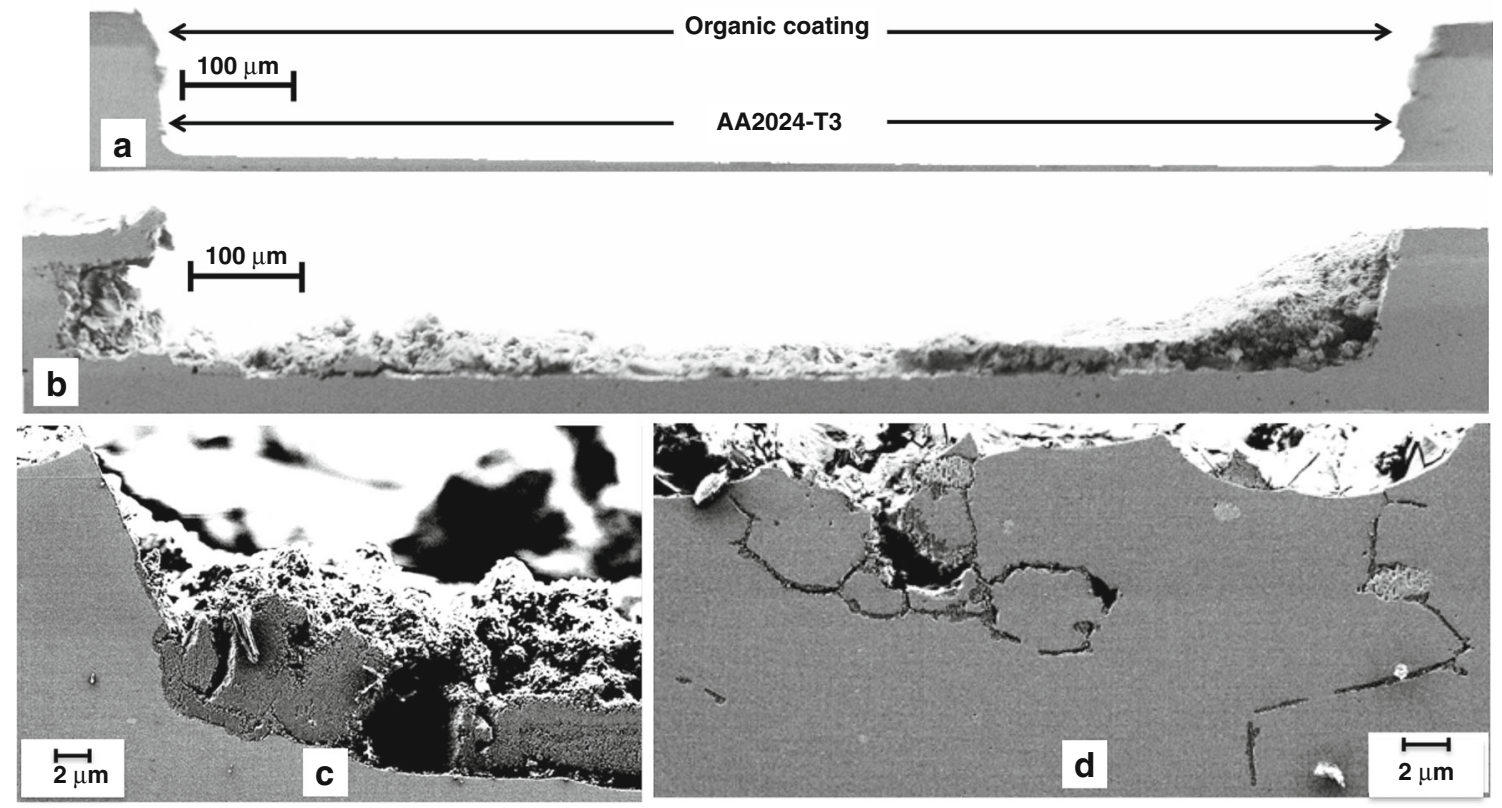

Fig. 2: Cross-section SEM images of scribed AA2024-T3 panels with a noninhibiting reference coating before and after $168 \mathrm{~h}$ neutral salt spray exposure (ASTM B-117): (a) full scribe unexposed, (b) full scribe after exposure, (c) detailed scribe area with corrosion products, and (d) intergranular corrosion ${ }^{47}$

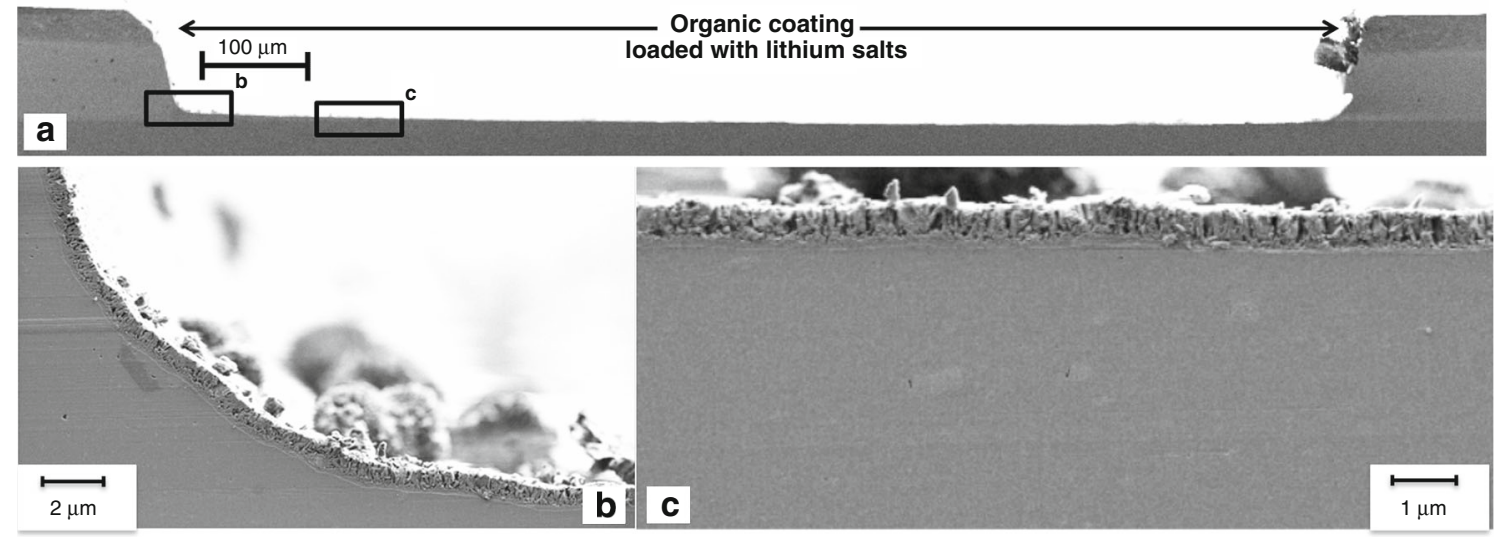

Fig. 3: Cross-section SEM images of protective layers generated from a lithium carbonate-loaded coating on AA2024-T3 after $168 \mathrm{~h}$ neutral salt spray exposure (ASTM B-117): (a) full scribed area, (b) curved area of bottom of the scribe, and (c) middle section of the scribe ${ }^{47}$

\section{Electrochemical evaluation of the corrosion protective properties}

The corrosion protective properties of the layers generated in the scribed area from these lithiumleaching coatings were investigated with electrochemical impedance spectroscopy (EIS) and potentiodynamic polarizations with the microcapillary cell technique.

EIS measurements were performed on scribed samples before and after NSS exposure. Liu et al. ${ }^{50}$ reported the EIS results of the lithium carbonate sample after $168 \mathrm{~h}$ of NSS exposure. Figure 5 shows the EIS results of both lithium salt-loaded samples compared to an unexposed sample and a sample without a corrosion inhibitor. The Bode plot of the impedance modulus (Fig. 5a) shows that both lithium salt containing samples display low-frequency impedance values that are about one order of magnitude higher compared to the noninhibited sample and the sample prior to exposure. The low-frequency impedance of the lithium oxalate-loaded sample is about 2 times higher compared to that of the lithium carbonate-loaded sample. In addition, the lithium-loaded 

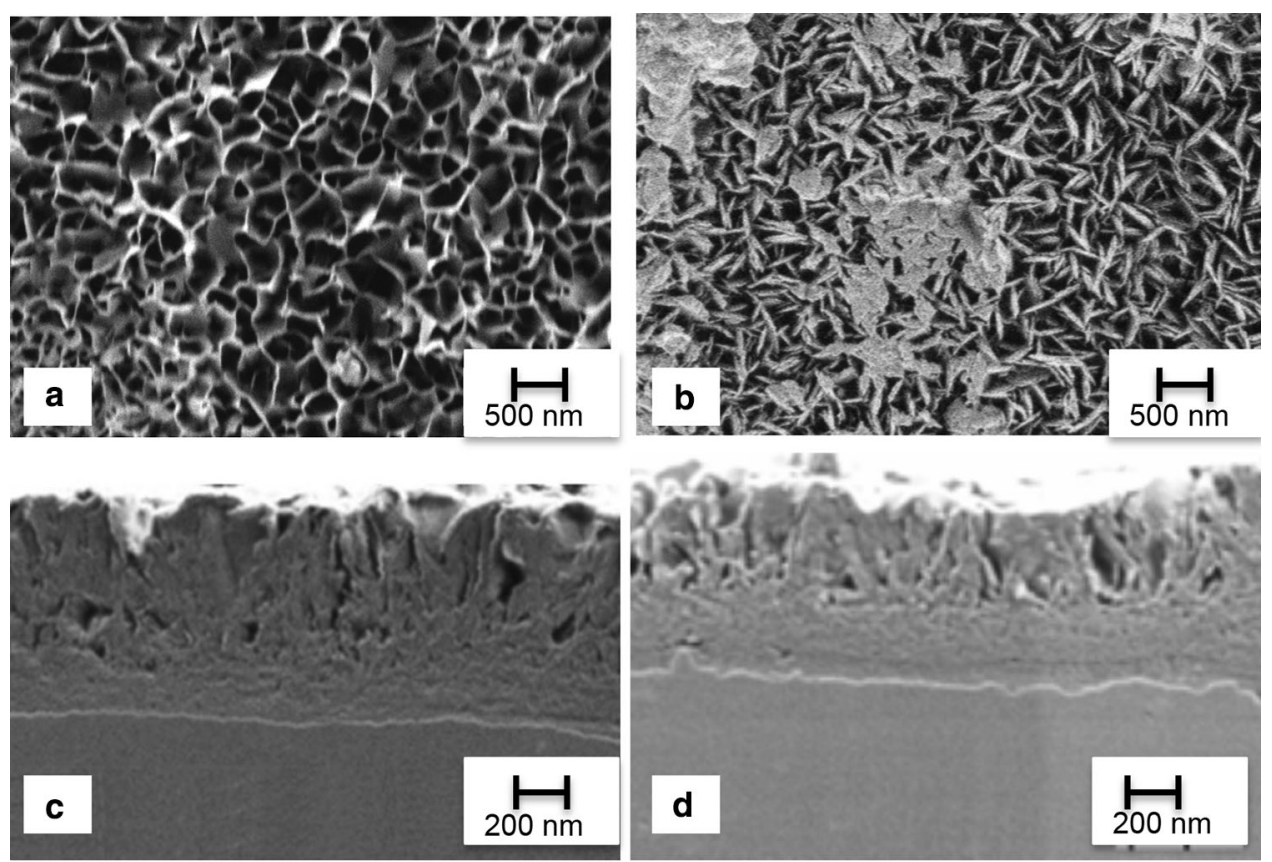

Fig. 4: SEM top-view and cross-sectional micrographs of protective layers generated from (a, c) lithium carbonate-loaded coating and $(b, d)$ lithium oxalate-loaded coating ${ }^{47}$

samples also display higher impedance values in the medium frequency range $\left(10^{0}-10^{2} \mathrm{~Hz}\right)$, which can be attributed to the formation of the protective film.

The Bode phase diagrams (Fig. 5b) show the increased and broadened phase angle values of the lithium salt-loaded samples after $168 \mathrm{~h}$ salt spray exposure compared to the phase angle values of the natural oxide film in the scribed area of the scribed but unexposed sample. This suggests the formation of a thicker and stable film in the scribed area during the exposure. In contrast, the noninhibiting sample also shows a broad but much lower phase angle range corresponding with a lower impedance modulus.

These EIS measurements after NSS exposure confirmed that the presence of lithium salts as a leachable inhibitor in coating results in the formation of a protective film in the scribed area.

Potentiodynamic polarization measurements were performed in the scribed area with the microcapillary cell technique. ${ }^{48}$ Figure 6 displays representative potentiodynamic polarization curves obtained with the microcapillary cell in the scribes of the samples containing lithium salts after $168 \mathrm{~h}$ NSS exposure and are compared to that of an unexposed scribe. The anodic polarizations were started $-50 \mathrm{mV}$ from the open circuit potential. When polarized, the unexposed sample has a corrosion current of approximate $1 \times 10^{-4} \mathrm{~A} / \mathrm{cm}^{2}$ and a breakdown potential of $-205 \mathrm{mV}$ vs $\mathrm{Ag} / \mathrm{AgCl}$. In contrast to this, the lithium-loaded samples show a reduced corrosion current compared the unexposed (natural oxide) of
$5 \times 10^{-5}$ and $1 \times 10^{-5} \mathrm{~A} / \mathrm{cm}^{2}$ for the lithium carbonate and lithium oxalate sample, respectively. In addition, the sample with a coating loaded with lithium carbonate was polarized up to $1500 \mathrm{mV}$ vs $\mathrm{Ag} / \mathrm{AgCl}$ before the breakdown potential (defined in this paper as the potential at which the anodic current density exceeds $1 \times 10^{-2} \mathrm{~A} / \mathrm{cm}^{2}$ ) was reached within the scribe area. The lithium oxalate sample could be polarized about $1000 \mathrm{mV}$ more before showing a breakdown potential at around $2500 \mathrm{mV}$ vs $\mathrm{Ag} / \mathrm{AgCl}$ proving the significant higher passivity induced by the lithium salt-based inhibitor leaching. This passive behavior corresponds with the EIS data where protection in the low and middle frequency range was clearly observed.

\section{Toward the mechanism of the formation of the protective layer}

The proposed mechanism of layer formation consists of several stages ${ }^{47}$ First, oxide thinning occurs when the damaged area is exposed to corrosive conditions, and alkaline conditions are generated in the scribe area upon relatively rapid release of the lithium salt-based inhibitors. ${ }^{51}$ Second, the formation of an amorphous aluminum hydroxide gel takes place due to the anodic dissolution of aluminum at the substrate-gel interface (growth process). ${ }^{52}$ Third, is the dissolution of the aluminum hydroxide gel at the gel-electrolyte interface. The balance between the formation and dissolu- 

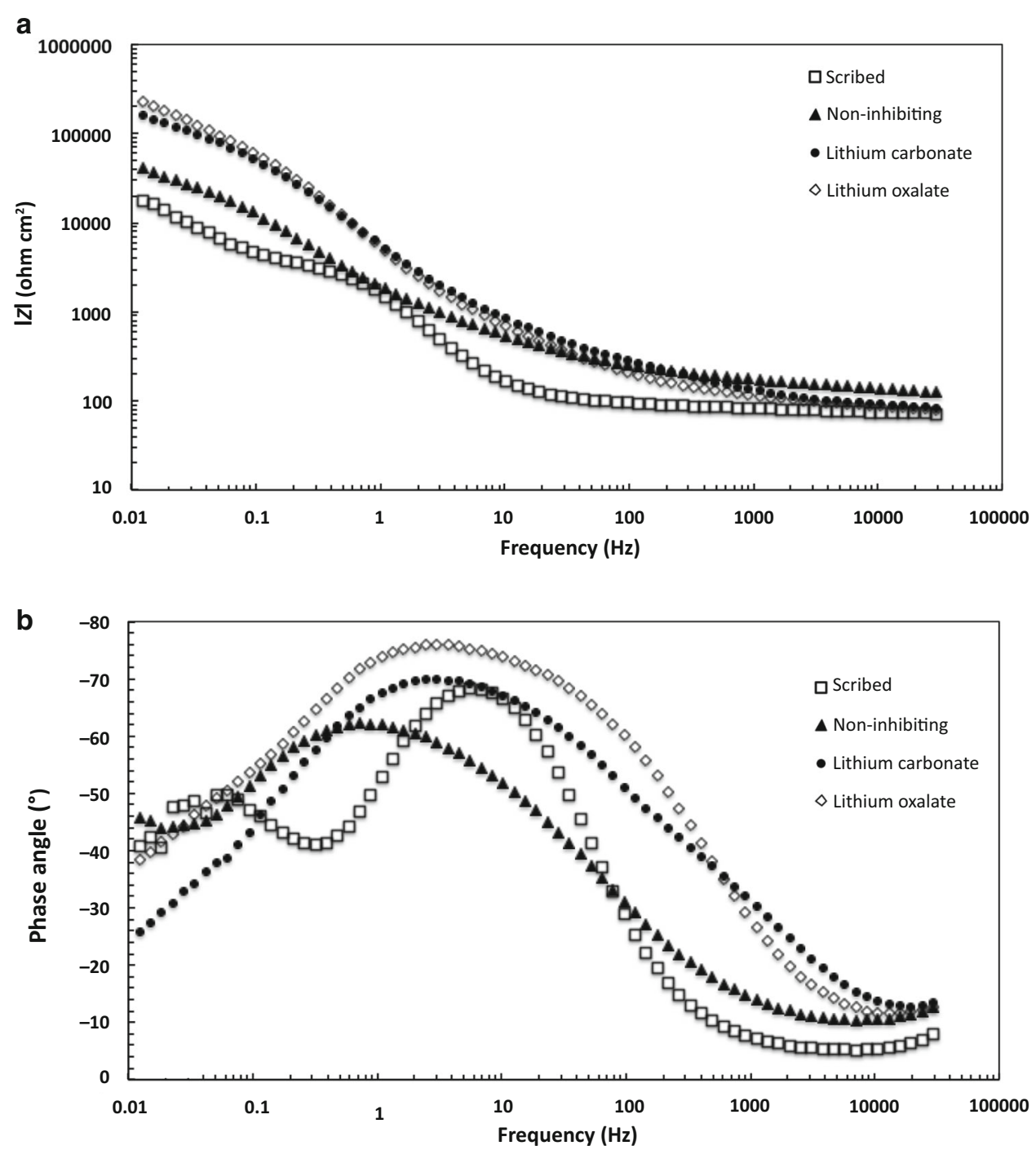

Fig. 5: (a) Bode impedance magnitude and (b) phase angle plots of electrochemical impedance spectra of the coated and scribed AA2024-T3 aluminum alloy in $0.05 \mathrm{M} \mathrm{NaCl}$ solution before and after $168 \mathrm{~h}$ neutral salt spray exposure

tion depends on the $\mathrm{pH}$ and hence, the thickness of the aluminum hydroxide gel depends on the alkalinity. ${ }^{53}$ The fourth and final process is the formation of the porous nonbarrier layer on top of the amorphous aluminum hydroxide gel. This may be the result of the dissolution/precipitation process (aging) process as postulated by Hurlen and Haug. ${ }^{54}$ These growth/ dissolution processes are in competition with each other and occur simultaneously until the formation is complete.

The formation of these protective layers from organic coatings in the damaged area is being studied in more detail to obtain more information about the mechanism involved. The release of lithium-ions from the coatings and the conditions in the scribe were monitored, and the formation of the layer was followed by microscopic techniques. Preliminary results show immediate release of lithium-ions and a significant

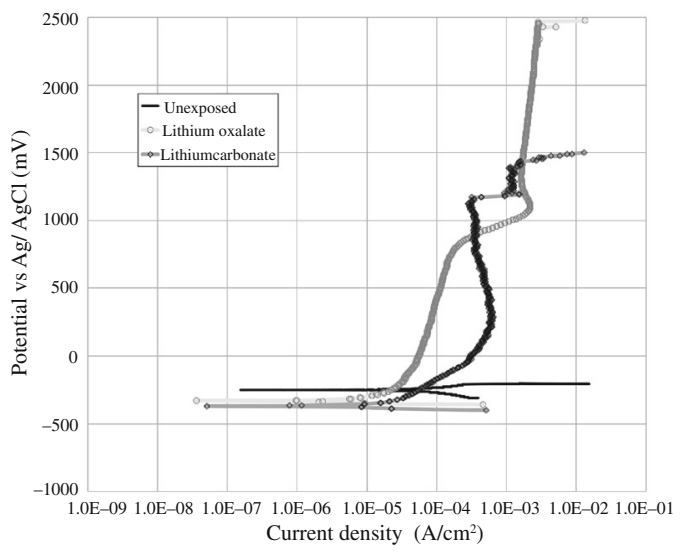

Fig. 6: Potentiodynamic polarization curves in $0.05 \mathrm{M} \mathrm{NaCl}$ solution measured with the electrochemical microcapillary cell in the scribe before and after $168 \mathrm{~h}$ neutral salt spray exposure 


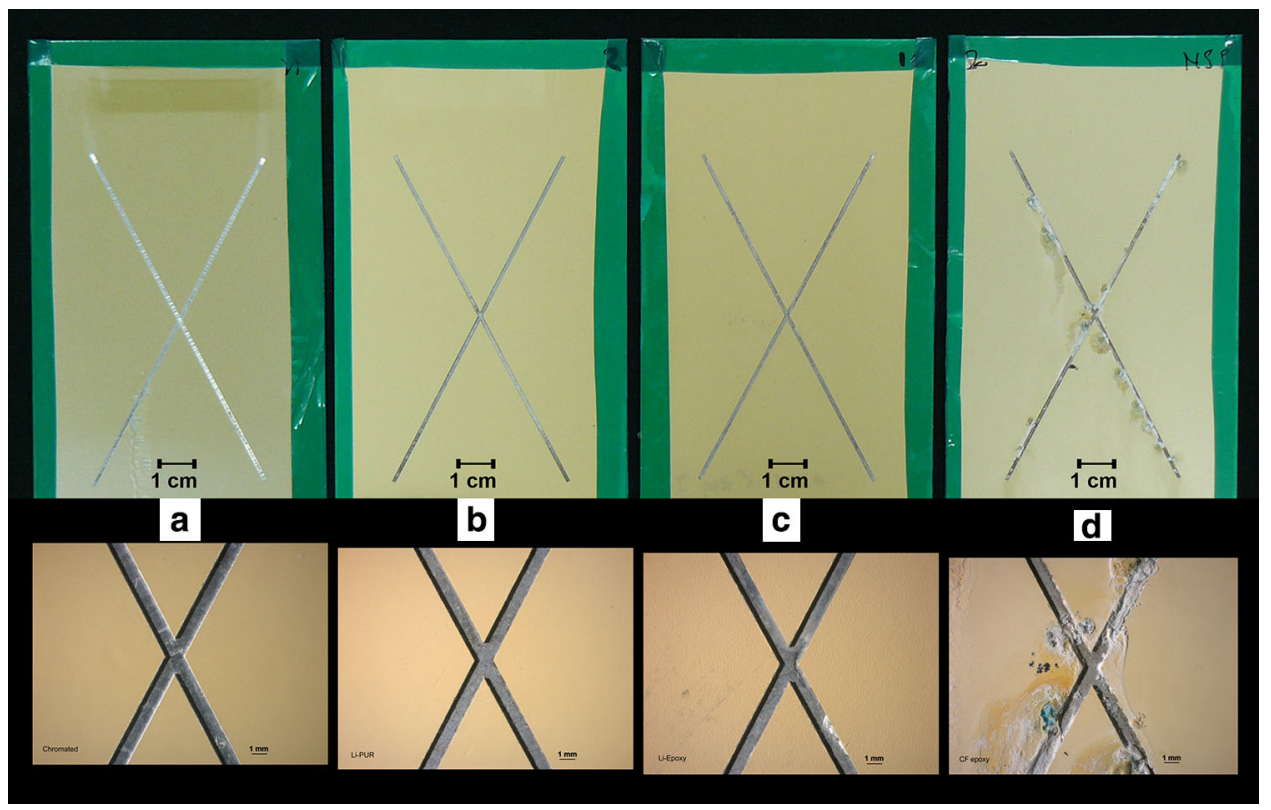

Fig. 7: Optical images of AA2024-T3 aluminum alloy coated with industrial coating concepts after $3000 \mathrm{~h}$ NSS exposure (top: entire panel; bottom: increased magnification): (a) chromated primer, (b) polyurethane-based primer with lithium salt inhibitor technology (c) epoxy-amine-based primer with lithium salt inhibitor technology, and (d) a previous generation chromate-free inhibitor technology

increase in alkalinity when the samples with lithium salt-loaded coatings were exposed to the electrolyte. ${ }^{55}$

\section{Lithium-based inhibitor technology in industrial applications}

Lithium salts were also incorporated in industrial primer systems and applied on AA2024-T3 bare aluminum alloy and exposed to industrial corrosion testing according to aerospace requirements to demonstrate industrial viability of this inhibitor approach. The systems were compared to a state-of-the-art chromated primer and a previous generation chromate-free primer. Figure 7 shows the appearance of the samples after $3000 \mathrm{~h}$ exposure to ASTM B-117 NSS conditions. The sample with a chromate-containing coating shows the well-known strong performance with a clean scribe, free of corrosion products. The previous generation chromate-free primer-coated sample (Fig. 7d) shows severe corrosion in the scribe and under-film corrosion adjacent to the scribe edges. The coatings with the lithium salt-based corrosion inhibiting technology show very good corrosion protection. The polyurethane shows (Fig. 7b) a slightly better performance in corrosion protection compared to the epoxy formulation (Fig. 7c). These results demonstrate that the lithium-leaching coating technology can be considered as a potential replacement of hexavalent chromium as corrosion inhibitor.

\section{Conclusions}

Organic coatings loaded with leachable lithium salts demonstrated effective corrosion inhibition AA2024T3 after NSS (ASTM B-117) exposure. Lithium-ions were able to leach from the coating matrix and a protective layer with a three-layered morphology was formed in the damaged area. The composition of the layer comprises aluminum, oxygen, and lithium. The formation of such a protective layer is based on a multistep competitive film growth and dissolution process. Corrosion inhibitive properties of these layers have been demonstrated with electrochemical techniques, and results of long-term corrosion testing with industrial concepts indicate that lithium salts shows high potential as a leaching corrosion inhibitor and may provide the industry with a new opportunity for the corrosion protection of aluminum alloys without the use of hexavalent chromium.

Acknowledgments The authors would like to acknowledge Agnieszka Kooijman for her assistance and help with the microcapillary cell experiments. This research was carried out under the collaboration agreement between Delft University of Technology and AkzoNobel.

Open Access This article is distributed under the terms of the Creative Commons Attribution 4.0 International License (http://creativecommons.org/li- 
censes/by/4.0/), which permits unrestricted use, distribution, and reproduction in any medium, provided you give appropriate credit to the original author(s) and the source, provide a link to the Creative Commons license, and indicate if changes were made.

\section{References}

1. Davis, JR, Corrosion of Aluminum and Aluminum Alloys. ASM International, Materials Park (1999)

2. Benavides, S, Corrosion Control in the Aerospace Industry. Woodhead Publishing, UK (2009)

3. Kaufman, JG, Introduction to Aluminum Alloys and Tempers. ASM International, Materials Park (2000)

4. Soutis, C, "Carbon Fiber Reinforced Plastics in Aircraft Construction." Mater. Sci. Eng. A, 412 (1-2) 171-176 (2005)

5. Muster, TH, Hughes, AE, Thompson, GE, Copper Dstributions in Al-Alloys in Corrosion Research Trends. Nova Science Publishers, New York (2007)

6. Boag, A, Hughes, AE, Glenn, AM, Muster, TH, McCulloch, D, "Corrosion of AA2024-T3 Part I: Localised Corrosion of Isolated IM Particles." Corros. Sci., 53 (1) 17-26 (2011)

7. Hughes, AE, Boag, A, Glenn, AM, McCulloch, D, Muster, TH, Ryan, C, Luo, C, Zhou, X, Thompson, GE, "Corrosion of AA2024-T3 Part II: Co-operative corrosion." Corros. Sci., 53 (1) 27-39 (2011)

8. Glenn, AM, Muster, TH, Luo, C, Zhou, X, Thompson, GE, Boag, A, Hughes, AE, "Corrosion of AA2024-T3 Part III: Propagation." Corros. Sci., 53 (1) 40-50 (2011)

9. Buchheit, RG, Grant, RP, Hlava, PF, McKenzie, B, Zender, GL, "Local Dissolution Phenomena Associated with S phase (Al2CuMg) Particles in Aluminum Alloy 2024-T3." $J$. Electrochem. Soc., 144 (8) 2621-2628 (1997)

10. Hughes, A, MacRae, C, Wilson, N, Torpy, A, Muster, T, Glenn, A, "Sheet AA2024-T3: A New Investigation of Microstructure and Composition." Surf. Interface Anal., 42 (4) 334-338 (2010)

11. Boag, A, Hughes, AE, Wilson, NC, Torpy, A, MacRae, CM, Glenn, AM, Muster, TH, "How Complex is the Microstructure of AA2024-T3?" Corros. Sci., 51 (8) 1565-1568 (2009)

12. Banis, D, Marceau, AJ, Mohaghegh, M, "Design for corrosion control." AERO. Boeing Commercial Airplanes Group Seattle (1999)

13. Bierwagen, G, "Next Generation of Aircraft Coatings Systems." J. Coat. Technol., 73 (915) 45-52 (2001)

14. Chattopadhyay, AK and Zentner, MKR, Aerospace and Aircraft Coatings. Federation of Societies for Coatings Technology, (1990)

15. Bierwagen, GP, "Reflections on Corrosion Control by Organic Coatings." Prog. Org. Coat., 28 (1) 43-48 (1996)

16. Xia, L, Akiyama, E, Frankel, G, McCreery, R, "Storage and Release of Soluble Hexavalent Chromium From Chromate Conversion Coatings. Equilibrium Aspects of CrVI Concentration." J. Electrochem. Soc., 147 (7) 2556-2562 (2000)

17. Kendig, MW, Buchheit, RG, "Corrosion Inhibition of Aluminum and Aluminum Alloys by Soluble Chromates, Chromate Coatings, and Chromate-Free Coatings." Corrosion, 59 (5) 379-400 (2003)

18. Pride, ST, Scully, JR, Hudson, JL, "Metastable Pitting of Aluminum and Criteria for the Transition to Stable Pit Growth.” J. Electrochem. Soc., 141 (11) 3028-3040 (1994)
19. Frankel, GS, McCreery, RL, "Inhibition of Al Alloy Corrosion by Chromates." Electrochem. Soc. Interface, 10 (1-4) 34-38 (2001)

20. Costa, M, Klein, CB, "Toxicity and Carcinogenicity of Chromium Compounds in Humans." Crit. Rev. Toxicol., 36 (2) 155-163 (2006)

21. National Toxicology P, "NTP 12th Report on Carcinogens." Report on carcinogens : carcinogen profiles/U.S. Dept. of Health and Human Services, Public Health Service, National Toxicology Program, 12, pp. 106-109 (2011)

22. Service, UPH, "Toxicological Profile for Chromium." Report No. ATSDR/TP 88/10 (1989)

23. Twite, RL, Bierwagen, GP, "Review of Alternatives to Chromate for Corrosion Protection of Aluminum Aerospace Alloys." Prog. Org. Coat., 33 (2) 91-100 (1998)

24. Sinko, J, "Challenges of Chromate Inhibitor Pigments Replacement in Organic Coatings." Prog. Org. Coat., 42 (3-4) 267-282 (2001)

25. Muster, TH, Hughes, AE, Furman, SA, Harvey, T, Sherman, N, Hardin, S, Corrigan, P, Lau, D, Scholes, FH, White, PA, Glenn, M, Mardel, J, Garcia, SJ, Mol, JMC, "A Rapid Screening Multielectrode Method for the Evaluation of Corrosion Inhibitors." Electrochim. Acta, 54 (12) 3402-3411 (2009)

26. Lopez-Garrity, O, Frankel, GS, "Corrosion Inhibition of Aluminum Alloy 2024-T3 by Sodium Molybdate." J. Electrochem. Soc., 161 (3) C95-C106 (2014)

27. Ralston, KD, Chrisanti, S, Young, TL, Buchheit, RG, "Corrosion Inhibition of Aluminum Alloy 2024-T3 by Aqueous Vanadium Species." J. Electrochem. Soc., 155 (7) C350-C359 (2008)

28. Iannuzzi, M, Young, T, Frankel, GS, "Aluminum Alloy Corrosion Inhibition by Vanadates." J. Electrochem. Soc., 153 (12) B533-B541 (2006)

29. Hughes, AE, Gorman, JD, Harvey, TG, Galassi, A, McAdam, G, "Development of Permanganate-Based Coatings on Aluminum Alloy 2024-T3." Corrosion, 62 (9) 773-780 (2006)

30. Aldykewicz, AJ, Jr, Isaacs, HS, Davenport, AJ, "Investigation of Cerium as a Cathodic Inhibitor for AluminumCopper Alloys." J. Electrochem. Soc., 142 (10) 3342-3350 (1995)

31. Hughes, AE, Markley, TA, Garcia, SJ, Mol, JMC, "Comparative Study of Protection of AA 2024-T3 Exposed to Rare Earth Salts Solutions." Corros. Eng. Sci. Technol., 49 (8) 674-687 (2014)

32. Treu, BL, Pinc, WR, Fahrenholtz, WG, O'Keefe, MJ, Morris, EL, Albers, RA, Characterization of Transport Processes in a Praseodymium-Containing Coating. Proc, Vancouver, BC (2010)

33. Zheludkevich, ML, Yasakau, KA, Poznyak, SK, Ferreira, MGS, "Triazole and Thiazole Derivatives as Corrosion Inhibitors for AA2024 Aluminium Alloy." Corros. Sci., 47 (12) 3368-3383 (2005)

34. Harvey, TG, Hardin, SG, Hughes, AE, Muster, TH, White, PA, Markley, TA, Corrigan, PA, Mardel, J, Garcia, SJ, Mol, JMC, Glenn, AM, "The Effect of Inhibitor Structure on the Corrosion of AA2024 and AA7075." Corros. Sci., 53 (6) 2184-2190 (2011)

35. Garcia, SJ, Fischer, HR, White, PA, Mardel, J, GonzalezGarcia, Y, Mol, JMC, Hughes, AE, "Self-Healing Anticorrosive Organic Coating Based on an Encapsulated Water Reactive Silyl Ester: Synthesis and Proof of Concept." Prog. Org. Coat., 70 (2-3) 142-149 (2011)

36. Mardel, J, Garcia, SJ, Corrigan, PA, Markley, T, Hughes, AE, Muster, TH, Lau, D, Harvey, TG, Glenn, AM, White, PA, Hardin, SG, Luo, C, Zhou, X, Thompson, GE, Mol, 
JMC, "The Characterisation and Performance of Ce(dbp)3Inhibited Epoxy Coatings." Prog. Org. Coat., 70 (2-3) 91101 (2011)

37. Garcia, SJ, Markley, TA, Mol, JMC, Hughes, AE, "Unravelling the Corrosion Inhibition Mechanisms of Bi-functional Inhibitors by EIS and SEM-EDS." Corros. Sci., 69 346-358 (2013)

38. Nanna, ME, Bierwagen, GP, "Mg-Rich Coatings: A New Paradigm for Cr-Free Corrosion Protection of Al Aerospace Alloys." JCT Res., 1 (2) 69-80 (2004)

39. Xu, H, Battocchi, D, Tallman, DE, Bierwagen, GP, "Use of Magnesium Alloys as Pigments in Magnesium-Rich Primers for Protecting Aluminum Alloys." Corrosion, 65 (5) 318-325 (2009)

40. Simoes, AM, Battocchi, D, Tallman, DE, Bierwagen, GP, "SVET and SECM Imaging of Cathodic Protection of Aluminium by a Mg-Rich Coating." Corros. Sci., 49 (10) 3838-3849 (2007)

41. Bierwagen, G, Brown, R, Battocchi, D, Hayes, S, “Active Metal-Based Corrosion Protective Coating Systems for Aircraft Requiring No-chromate Pretreatment." Prog. Org. Coat., 67 (2) 195-208 (2010)

42. Gui, J, Devine, TM, "Influence of Lithium on the Corrosion of Aluminum." Scr. Metall., 21 (6) 853-857 (1987)

43. Drewien, CA, Eatough, MO, Tallant, DR, Hills, CR, Buchheit, RG, "Lithium-Aluminum-Carbonate-Hydroxide Hydrate Coatings on Aluminum: Composition, Structure and Processing Bath Chemistry." J. Mater. Res., 11 (6) 1507-1513 (1996)

44. Rangel, CM, Travassos, MA, "The Passivation of Aluminium in Lithium Carbonate/Bicarbonate Solutions." Corros. Sci., 33 (3) 327-343 (1992)

45. Buchheit, RG, Bode, MD, Stoner, GE, "Corrosion-Resistant, Chromate Free Talc Coatings for Aluminum." Corrosion, 50 (3) 205-214 (1994)
46. Visser, P and Hayes, SA, "WO2010112605-A1."

47. Visser, P, Liu, Y, Zhou, X, Hashimoto, T, Thompson, GE, Lyon, SB, van der Ven, LGJ, Mol, AJMC, Terryn, HA, "The Corrosion Protection of AA2024-T3 Aluminium Alloy by Leaching of Lithium-Containing Salts From Organic Coatings." Faraday Discuss., 180 511-526 (2015)

48. Suter, T, Böhni, H, "A New Microelectrochemical Method to Study Pit Initiation on Stainless Steels." Electrochim. Acta, 42 (20-22) 3275-3280 (1997)

49. Liu, PV, Zhou, X, Lyon, SB Hashimoto, T, Gholini, A, Thompson, GE, Smyth, G, Gibbon, SR, Graham, D, Mol, JMC, Terryn, HA "An Investigation of the Corrosion Inhibitive Layers Generated From Lithium Oxalate-Containing Organic Coating on AA 2024-T3 Aluminium Alloy. Surf. Interface Anal. (2016, accepted)

50. Liu, Y, Visser, P, Zhou, X, Lyon, SB, Hashimoto, T, Curioni, M, Gholinia, A, Thompson, GE, Smyth, G, Gibbon, SR, Graham, D, Mol, JMC, Terryn, H, "Protective Film Formation on AA2024-T3 Aluminum Alloy by Leaching of Lithium Carbonate from an Organic Coating." J. Electrochem. Soc., 163 (3) C45-C53 (2016)

51. Foley, RT, "Localized Corrosion Of Aluminum Alloys: A Review." Corrosion, 42 (5) 277-288 (1986)

52. Foley, RT, Nguyen, TH, "The Chemical Nature of Aluminum Corrosion: V. Energy Transfer in Aluminum Dissolution." J. Electrochem. Soc., 129 (3) 464-467 (1982)

53. Baes, CF, Mesmer, RE, The Hydrolysis of Cations. Wiley, New York (1976)

54. Hurlen, T, Haug, AT, "Corrosion and Passive Behaviour of Aluminium in Weakly Alkaline Solution." Electrochim. Acta, 29 (8) 1133-1138 (1984)

55. Visser, P, Lutz, A, Mol, JMC, Terryn, H, "Study of the Formation of a Protective Layer in a Defect From Lithium-Leaching Organic Coatings." Prog. Org. Coat. (2016, submitted) 